\title{
Personal Statements written by Chinese and English-speaking applicants: a Study on Move-Step Arrangements and Word Distribution
}

\author{
Zhanni Luo \\ School of Educational Studies and Leadership \\ University of Canterbury \\ Christchurch, 8041, New Zealand
}

\begin{abstract}
:
Personal statement (PS), an academic promotional document, plays an important role in undergraduate and postgraduate admission application in most English-speaking countries. However, applicants suffer from unfamiliarity with this particular type of writing because few samples and little guidance are available. Applicants of non-native speakers, for example, Chinese, are more disadvantaged due to language barriers and cultural differences. In the current study, this author collected 15PSs written by Chinese applicants and 15 by Englishspeaking applicants for the application of Master's study in English-speaking countries. Based on the 30 PSs, this author summarized a move-and-step framework which reveals the writing differences of Chinese and Englishspeaking applicants. Since the personal statements by Chinese applicants are reported being too long, this author investigated participants' word allocation in each move and gave suggestions accordingly. This study can be helpful for the instruction of academic writing of this genre; it can also develop our understanding of the cultural differences between China and English-speaking countries.
\end{abstract}

Keywords: Personal Statement (PS); Genre Analysis; Move-Step Analysis; Academic Writing; Applied Linguistic

\section{Introduction}

Nowadays in China, increasingly more students are planning to study in English-speaking countries, which highlighted the importance of training on the writing of personal statements. Personal statement (PS), an academic promotional genre(Bhatia, 2014), "serves as a part of the application for admission to higher education institutions" (Chiu, 2016, p. 48) that allows applicants to show their personalized characteristics to standout themselves from other competitors. To be noted, PS is not commonly required for admission to educational institutions in Chinesespeaking countries, but essential for that in English-speaking countries.

In the writing of this specific genre, Chinese applicants present obvious differences due to varied language and cultural styles, which might not align with decision-makers' preferences. For example, Chinese applicants eager to promise repayment such as 'sponsor my alma mater', which might not be valued by the admission committee. Furthermore, the average word count for Chinese applicants' PSs is 669 the research ofJ. Liu (2012), which is "long" and "risky" for admission officers(Crimson, 2004, p. 99). However, there is neither sufficient research discussing the characteristics of Chinese applicants' PSs nor systematic research on how many words should a PS contains(Chiu, 2016; Ding, 2007).

To address the aforementioned gaps, this author conducts a genre analysis to investigate the differences in PSs written by Chinese and English speaking applicants through the lens of a move-step analysis. 'Move' is a linguistic concept and a functional unit in a text to serve for a specific purpose(Connor, Davis, \& De Rycker, 1995). There is a regular pattern of 'moves' and 'strategies' (also be called 'steps' in later research) in a certain order in the systematical studies of research settings(J. Swales, 1996), and the move-step analysis applies to PS studies.

This author establishes a move-step framework of PS writing, analyzed the writing differences of Chinese and English-speaking applicants, and assessed the word count of the two groups based on the standards valued by native speakers. The findings help Chinese students to compete with native applicants who are already at an advantage position (Henry \& Roseberry, 1997). Moreover, considering PS as a combination of a series of moves and analyzing the move arrangement, this study can offer a learning pattern from a teaching perspective.

This investigation aims to address three research questions: what are the differences in the move-step arrangement between PSs written by Chinese applicants and English-speaking applicants? Does the word count of PSs written by Chinese applicants exceed standards? If the PSs written by Chinese applicants are long, on which move it can be cut down?

\section{Literature Review}

\subsection{The Writing of Personal Statement (PS)}


In a graduate school application in most English-speaking countries, the personal statement (PS), or the graduate school application letter(Ding, 2007), serves as a crucial document(Brown, 2004). The PS is "the most personal element of the residency application" (Ostapenko, Schonhardt-Bailey, Sublette, Smink, \& Osman, 2018, p. 576), which enables an applicant to give more information about themselves that "may not (be) covered in the other areas of the application" (Lee et al., 2008, p. 170). By presenting personal characteristics and individualized strengths, the PS helps applicants to distinguish themselves from other competitors.

The writing of PS is difficult for applicants due to its occluded nature(J. Swales, Feak, Barton, \& Brown, 2004). Occluded genres refer to "typically formal documents which remain on file" for a limited number of audiences, and therefore, rarely accessible for the public (J. Swales, 1996, p. 46). In other words, the material or feedback of the genre is not available for open access $(\mathrm{He}, 2010)$. Since newcomers of a field "have read few, and written even fewer, documents of this kind" (Brown, 2004, p. 243), "they have no adequate knowledge of the context" (Ding, 2007, p. 387), neither balanced knowledge or familiarity with the format (Brown, 2004; J. Swales, 1996; J. Swales et al., 2004). Most seriously, there is a lack of proper training on the writing of this genre. According to Brown (2004), PS writing is involved in "nowhere in college curricula" (p. 243) while books or online materials fail to offer systematic directions or discipline-specific samples, not to mention personalized advice (Brown, 2004; J. Liu, 2012).At the same time, even though applicants and those who would like to help are expecting guidelines in PS writing, they feel "short of theoretical and disciplinary guidance of personal statement writing" (Li \& Deng, 2019, p. 70) since few academic studies have been conducted in this field.

In PS writing, non-native applicants suffer from language barriers, cultural differences as well as inadequate knowledge. The study of Max, Gelfand, Brooks, Beckerly, and Segal (2010) reveals that applicants with better language ability are more likely to enter the next round of selection, while the language ability refers to not only the correct usage of grammar but also good word selection and the overall organization. Since most of the decisionmakers or "gatekeepers" are native speakers, non-native applicants' characterized word selection and sentence structures can be easily detected (Crimson, 2004). Even though sometimes the sentences written by non-native applicants are grammatically correct, it can be "awkward" due to writers' unfamiliarity with the English language and its culture. Furthermore, audience expectations of PSs are often "more shaped by local cultural values and national academic traditions than is the case with more technical writing" (J. M. Swales \& Feak, 1994, p. 229), which make the lack-of-guide Chinese applicants even more disadvantaged (J. Swales, 1996).

It can be inferred from the above discussions that non-native applicants such as Chinese need more guidance on PS writing. Both from the perspective of teaching writing or carrying out culture analysis, the first step is to understand the writing characteristics of Chinese applicants and the standards valued by native speakers from English-speaking countries.

\subsection{Previous Studies on the Move-step Arrangement of PS Writing}

The majority of the existing PS studies adopt a genre-based move-step analysis proposed by J. Swales (1990)to identify rhetorical features (Chiu, 2015; Li \& Deng, 2019). The term genre has been defined as a form of discourse with "shared style, content and intended audience"(J. Swales, 1990, p. 58) to "achieve certain communicative purposes" (Ding, 2007, p. 369). In analyzing a genre, attention is directed to move-step analysis(Nodoushan \& Montazeran, 2012). A 'move' refers to a functional unit in texts to identify the "textual regularities in certain genres of writing" (Ding, 2007, p. 369). Move identification and description are the "inevitable parts" of genre analysis (He, 2010, p. 6), asJ. Swales (1996)indicates that there is a regular pattern of "moves" that appear in a certain order in academic writing. By detecting the regular patterns, researchers can compare or contrast texts of different contexts. A 'step' is "a lower-level text unit than the move that provides a detailed perspective" on writers' options in choosing the themes of what s/he wishes to communicate (Dudley-Evans, St John, \& Saint John, 1998, p. 89). In other words, 'step' is a concept to realize a more detailed move(Henry \& Roseberry, 1997), which is viewed as a subscale of the functional unit "move". Some researchers also use other terms to indicate the same meaning, such as Ostapenko et al. (2018) using the term 'common topic' to refer to 'move' and Bhatia (2014) using the term 'strategy' to refer to 'step'.

Move-step analysis is applicable in academic writing analysis including research articles, abstracts, proposals and business letters. According to Chiu (2015),personal statements, even though with the expectation of being 'personal', "can be contextualized as a form of academic writing since its purpose is to communicate with an academic audience and it is also considered as a type of writing sample that academics will use to evaluate a student's written ability" (p. 72). Therefore, move-step analysis applies to PS studies.

One typical move-step framework is proposed by Chiu (2016), which contains five moves and 22 steps. In the framework, applicants firstly introduce him/herself with personal background, research interests or generalization about the discipline in Move 1, followed by the introduction of relevant background (Move 2), including academic achievements and experiences, work experiences, research interests, language and cultural proficiency and background (travel, family and personality). Move 3 is 'reasons for applying' consisting of five steps, namely gap 
in applicant background, personal ambition, programme and university attributes/understanding, self-reflection, and disciplinary or research reasons.

Move 4 is extra-'curricular information' without steps, followed by the Move 5 'conclusion'. In concluding a PS, applicants tend to predict their future success, promote themselves, express their understanding of the proposed study, praise for the institution, or mention their possible contribution to the course. Ding analyzed 30 PSs for medical/dental school application and identified five moves, namely reasons for studying medicine, credentials, relevant life experiences, future career goals and personalities. The moves and steps proposed by Ding (2007) are mostly covered in those proposed by Chiu (2016), so this author selects the one by Chiu (2016).

Chinese researchers initial most PS studies that involve PSs written by Chinese applicants. Bu (2008) presented is a compressive framework containing seven moves and 10 steps. The findings are representative for Chinese applicants' characteristics, such as the step of 'introducing growth environment' and 'portraying events which shape personalities'. However, the author collected samples from the Internet, which weakens the authenticity and diversity of the samples. Accordingly, the data shows a high degree of similarity, such as $100 \%$ appearance of the move 'salutation' and 'ending', which do not apply to other PSs. As to other articles, there is a lack of representative articles that are published in academic journals with a high reputation. T. Liu (2008) studied PSs from a linguistic perspective, such as hematic structure and notional verb. However, the final paper is only three pages so the author did not justify her choice of the moves in detail. Similarly, Xu (2014) enlisted a framework with seven moves and 16 steps without clarifying the process of framework establishment. Fan and Wang (2008) presented four moves of Chinese applicants (Bio history, Motivation, Advantages, and Purpose) and three moves of American applicants (Purpose, Advantages and Restate the wish) in a Master's dissertation. The moves proposed by Fan and Wang (2008) are too general to be significant for future studies.

To address the aforementioned issues, the current study aims to collect successful-accepted samples directly from applicants, as well as explain the establishment of the move-step framework in detail. To be noted, the aforementioned frameworks are based on PSs for the application of diverse degree, so those for Ph.D. applications emphasize on academic experience and credentials (Chiu, 2015; Ding, 2007), while others highlight other information as well, such as hobbies and interest, extra-curriculum experience, volunteer experience and life story (Fan \& Wang, 2008; He, 2010; Xu, 2014). PSs for undergraduate study tend to tell stories and "create an image" (Crimson, 2004, p. 18), which is close to story-telling, while PSs for doctoral study mainly aims to explain research interests and experiences (Brown, 2004), which is close to the statement of a research plan. This author believes that PSs for the Master's study is a balance of the two, which provide more insightful information in identifying applicants' natural selection of moves and steps. Therefore, the current study collects PS samples for Master's study only.

\subsection{Word Limit of PS Writing}

There is an on-going debate on how many words should a PS contains, and the results given by Chinese websites are not coherent with the standards.

In English-speaking countries, there are several platforms offering word limit standards. The Universities and Colleges Admissions Service (UCAS) is a central organization through which process applications for entry to higher education in British universities. UCAS offers an online checking system, which accepts PSs with a maximum of 4000 characters (equivalent to 500 words)(Sexton, 2018). The website Common Application, with which applicants can apply to nearly 700 colleges and universities, provides a standard of 250-650 words(Grove, 2018). Crimson (2004) published a book titled50 Successful Harvard Application Essays: what worked for them can help you get into the college of your choice, in which the word limit is specifically suggested as "500 words"(p. $3)$. Generally, even though the standard varies from one to another, the word account of 500-650 words is the widely acknowledged standard.

Meanwhile, Chinese applicants receive controversial information from websites in the Chinese language. The BBC (2016) news China states that there is no word limit for PSs. It suggests that it is acceptable to submit a long PS (if it is outstanding). Website The Share (2018) published an article in which the suggested word limit is 1000. Even though some websites understand the standards in English-speaking countries, they still give improper suggestions. For example, OfferMachine (2012) clearly states "many universities set the word limit as 300-500 words, even within 3500 characters", and immediately suggests that "the PS should be around 800 words", which exceeds the given standards. Surprisingly, a professional PS writing agency named Essay Edge also proposes that PSs should be between 500-1000 words (Funderburk, 2018). Overall, the word limit recognized by Chinese applicants is around $800-1000$ words.

The word limit standards given by Chinese websites are also higher than the results of the empirical studies on successful applications. The average length of successful PSs in the study of T. Liu (2008) and Ding (2007) is 567 and 692 words respectively, and that in the study of Chiu (2007) is around 750 words. Even though the research objectives in Chiu (2016) are PSs with more complex contents (for doctoral application), the word limit is still lower than that advocated by Chinese websites (800-1000 words). Ostapenko et al. (2018) analyzed 578 PSs for the 
application of medical/surgery programs, and the total words of these PSs are 382,405 . On average, the word count for each PS is 661 only.

There is a huge gap in the understanding of word limit for PSs and the related studies are scarce. This study will fill the gap with two explorations. Firstly, the word counts of PSs written by Chinese and English-speaking applicants are compared with UCAS standards (4000 characters); secondly, the total words distributed to each move are calculated. The findings can indicate whether Chinese applicants write longer than expected and in which part the PSs can be more concise.

\section{Methodology}

\subsection{Participants and considerations in data collection}

The sample size of PS studies is comparatively small due to the occlude nature of this genre and the corresponding ethics concerns. Brown (2004) analyzed the features distinguishing successful PSs and the rejected ones, and the number of samples of each type is nine only. Later on, Ding (2007) identified the 'move' arrangement of 30 PSs for medical/dental school application, in which 20 are the successful ones and 10 are unsuccessful ones. Chiu (2016)conducted a genre analysis to explore the rhetorical patterns of structures of the PSs submitted to two universities, and the total number of PSs involved is 21. Some Chinese researchers also conduct their PS studies with a sample size of 30 . There are also researchers obtaining a large sample size in their studies, for example, Max et al. (2010) involved 670 PSs for anesthesiology residency application. However, these studies rely on the accessibility of the PSs pool managed by the admission committee on the condition that a large portion of admission committees refuse to share the PSs out ethics concerns. The same with most other researchers have done, this author arranges 30 pieces of PSs in the current study, in which 15 are written by Chinese applicants and 15 are by English-speaking applicants.

The selected PSs meet the following requirements: 1) all the samples are for Master's study application, 2) all the samples must be directly collected from applicants, 3) the samples must be completed without limitations on the structure and 4) the samples must be those being successfully admitted (see Table 1). PSs for undergraduate, Master's, and doctoral applications are different from each type: PSs for undergraduate study tend to tell stories and "create an image" (Crimson, 2004, p. 18), PSs for doctoral study mainly aim to explain research interests (Brown, 2004), and the PS for the Master's study is a balance of the two. At the same time, applicants must be Chinese citizens without living in English-speaking countries for more than one year or those who speak English as their mother language or the first language. To minimize bias brought by variables, the English-speaking countries are limited to the United Kingdom and the United States of America, both for the location of universities and the hometown of native applicants.

It worth noticing that disciplinary variation is an inevitable concern in comparative studies: the admission officers in business schools might hope to know more about the applicants' internship experience while officers in medical schools prefer students demonstrating strong academic potential. There is no evidence proofing that disciplinary variation affects the selection of moves or steps, however, it is obvious that disciplinary variation brings significant differences in word distribution due to varied value on each move or step. To control variables, some researchers choose to select PSs for a specific subject, such as medical/dental studies, such as Chiu (2015) and Ding (2007). However, again, PS is an occluded document, which means the material or feedback is not available for open access (He, 2010). Together with the fact that the number of Master students in each subject is limited, this author comes across with difficulties in data collection. As a compromise, this author selects15 PSs for the application of three subjects (Educational, Engineering and Design) from each group (Chinese applicants and English-speaking applicants), with five PSs for each subject. The selection of the three subjects is based on the convenience sampling principle (see Table 1).

Following ethical consideration, all participants had given approvals before they agreed to take part. All the participants were more than 18 years old and were eligible to participate in the research project individually. To avoid readers inferring the participants' identity through the textual information presented in Table 2, this author extracts examples from PSs written by various applicants. The chosen textual examples from one certain applicant's PS are no more than 5\% of the whole document. Before that, this author deleted participants' personal information from the original documents at the beginning of data analysis. 
Table 1. Considerations in sample selection

\begin{tabular}{ll}
\hline \multicolumn{1}{c}{ Selection requirements } & \multicolumn{1}{c}{ Reasons } \\
\hline PSs for Master's study & $\begin{array}{l}\text { To guarantee a balance of story-telling and } \\
\text { research-related statements } \\
\text { Po guarantee the authenticity and reliability of } \\
\text { the data } \\
\text { To guarantee the natural selection of moves and } \\
\text { steps }\end{array}$ \\
PSs be written without limitation on the structure & $\begin{array}{l}\text { To guarantee the quality of data } \\
\text { To guarantee the cultural characteristics of } \\
\text { participants } \\
\text { Successful PSs } \\
\text { Controlled language background of the applicants } \\
\text { variation }\end{array}$ \\
A controlled number of PSs in three certain caused by disciplinary \\
subjects
\end{tabular}

\subsection{The establishment of the move-step framework}

This author establishes a comprehensive framework based on previous research with the following procedures, as shown in Figure 1.

Firstly, this author selects a basic framework in which the expressions of moves and steps serve as a "coding protocol" (Chiu, 2016, p. 51). In considering representativeness and generalizability, the framework proposed by Chiu (2016) was chosen to offer move-step categorization and definitions.

Then, this author removes moves or steps that are not significantly applicable for the objective of this research, such as "stating one's understanding of medicine/dentistry" that serves for doctoral application in the study of Ding (2007, p. 376) and "language and cultural proficiency" which applies to the study of Chiu (2016, p. 52) rather than in the current one.

After that, this author merges related move-step frameworks into the chosen one. At this step, the expressions in the framework of Chiu (2016) were chosen as the priority for consistent expressions of the moves or steps. If there are new moves or steps that not covered in the framework of Chiu (2016), this author creates new moves or steps in the initial framework.

Fourthly, this researcher moves back and forth between the collected PS samples and the ongoing move-step classification to "identify and (re)define functional units which represented a particular communicative purpose" (Chiu, 2016, p. 51).If the moves/steps in the framework were not confirmed in the PS samples, they will be regarded as invalid and then be deleted. At this step, it is possible to identify moves or steps that are not covered in the initial framework, so this author goes back to the first step to check with the moves/steps in all related frameworks. The final move-step framework confirms when there are no new functional units detected, nor are uncovered units in the collected PS samples (see Figure 1). 


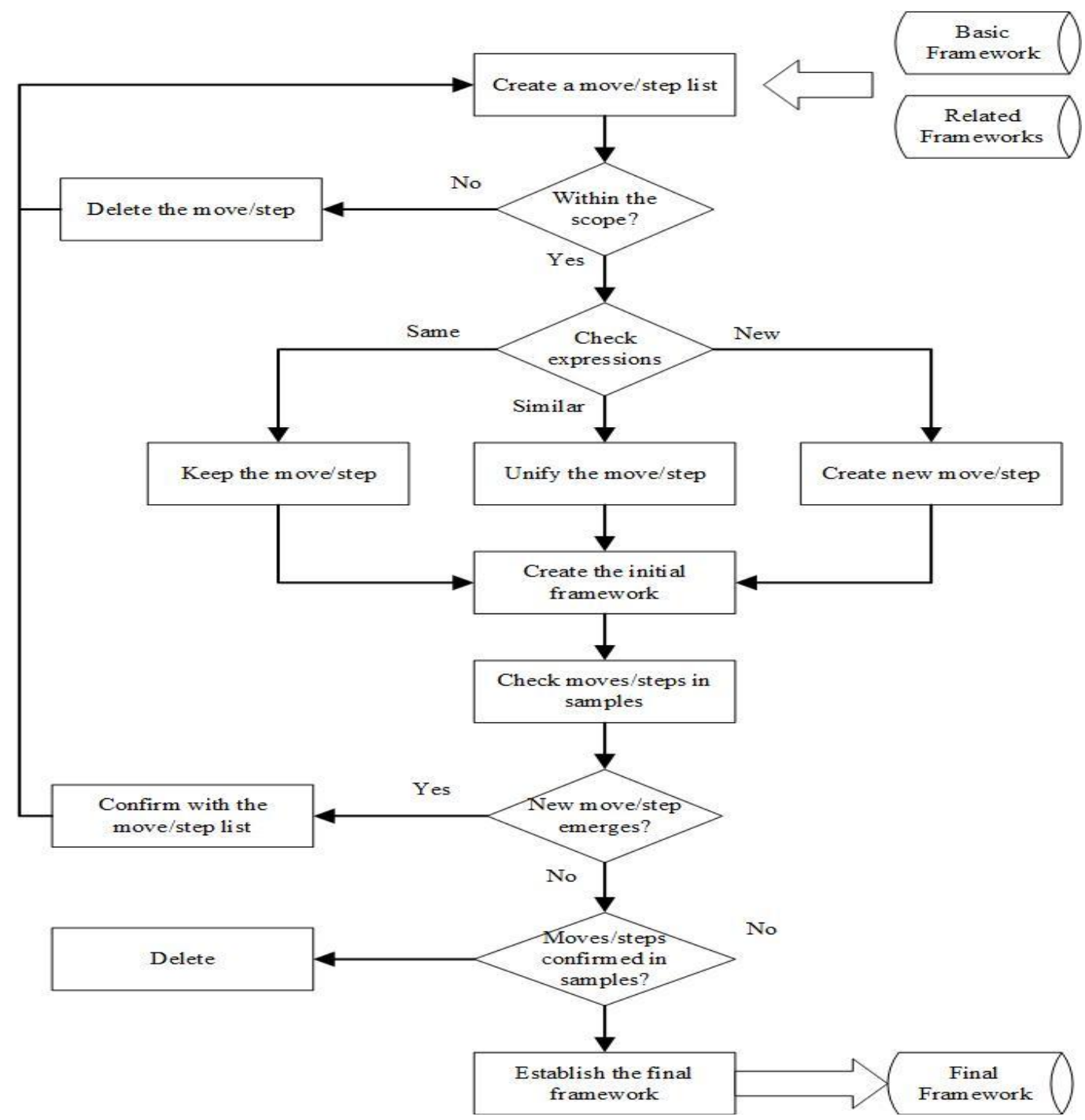

Figure 1. Process of the move-step framework establishment

After the establishment of the framework, the corresponding coding system was organized. In the coding system, the Arabic numbers refer to moves while the English alphabets represent steps. For example, 4-B refers to Move 4 Step 2. All the samples were hand-tagged in the software Nvivo. This author uses CA1 to CA15 to refer to the 15 Chinese applicants and EA1 to EA15 to refer to the 15 English-speaking applicants.

The line count and character count of PSs were checked by the online UCAS checking system, which indicates that a PS should be less than 47 lines or 4000 characters(Sexton, 2018). To make the results easier to understand, this researcher also calculates the word counts besides the number of characters. The adopted word limit standard is offered by the Common Application, which is 250-650 words(Grove, 2018). The number of both characters and word count was calculated by Microsoft Word.

This author also calculates the occurrence of each step in the PSs submitted by Chinese and native English speakers. The repeated steps do not count in move/step occurrence calculation. For example, among 15 Chinese applicants, 'Bio History' (Step 2-B) showed up in 11 statements for 37 times, the occurrence was $73 \%$ (11 divides by 15 ) instead of $247 \%$ (37 divides by 15 ).

\subsection{Reliability and Validity}

As supported by Chiu (2016)for the enhance inter-rater reliability in "categorizing a text segment" (Lim, 2019, p. 38), this author employs two other raters to analyze and code the sentences in the corpus. Both of the two raters are $\mathrm{Ph} . \mathrm{D}$. candidates with a linguistic background. The raters were briefed on the coding method and the move-step framework, then code independently according to their understanding of the context. This process is to ensure the coding system was translated accurately with considerable coherency and minimal misunderstandings. After obtaining the three sets of coding results, this author organizes a meeting to discuss the differently coded moves or steps, and eventually reached an agreement to the result (see Table 2). 


\section{Findings}

Table 2. Frequency of moves and steps for PSs written by CA and EA

\begin{tabular}{|c|c|c|c|c|c|}
\hline \multirow[t]{2}{*}{ Moves and steps } & \multicolumn{2}{|c|}{ CA } & \multicolumn{2}{|c|}{ EA } & \multirow{2}{*}{$\frac{\text { Difference }}{\%}$} \\
\hline & $\mathrm{N}$ & $\%$ & $\mathrm{~N}$ & $\%$ & \\
\hline \multicolumn{6}{|l|}{ Move 1: Introduction } \\
\hline Step 1-A: Opening & 2 & $13 \%$ & 3 & $20 \%$ & $-7 \%$ \\
\hline Step 1-B: Childhood/Youth & 11 & $73 \%$ & 0 & $0 \%$ & $73 \%$ \\
\hline Step 1-C: Family and the influence & 9 & $60 \%$ & 1 & $7 \%$ & $53 \%$ \\
\hline Step 1-D: Personality-shaping events & 14 & $93 \%$ & 4 & $27 \%$ & $66 \%$ \\
\hline Step 1-E: Personal strengths & 10 & $67 \%$ & 12 & $80 \%$ & $-13 \%$ \\
\hline \multicolumn{6}{|l|}{ Move 2: Reasons to pursue study } \\
\hline Step 2-A: The development of interests & 12 & $80 \%$ & 10 & $67 \%$ & $13 \%$ \\
\hline Step 2-B: Exceptional gifts & 1 & $7 \%$ & 0 & $0 \%$ & $7 \%$ \\
\hline Step 2-C: Relevant life experiences & 15 & $100 \%$ & 5 & $33 \%$ & $67 \%$ \\
\hline Step 2-D: Related achievements (non-academic) & 13 & $87 \%$ & 5 & $33 \%$ & $53 \%$ \\
\hline \multicolumn{6}{|l|}{ Move 3: Evidence of academic qualification } \\
\hline Step 3-A: Educational background & 15 & $100 \%$ & 15 & $100 \%$ & $0 \%$ \\
\hline Step 3-B: Research experiences & 7 & $47 \%$ & 13 & $87 \%$ & $-40 \%$ \\
\hline Step 3-C: Work/intern experiences & 9 & $60 \%$ & 10 & $67 \%$ & $-7 \%$ \\
\hline \multicolumn{6}{|l|}{ Move 4: Other information } \\
\hline Step 4-A: Personal interests and hobbies & 2 & $13 \%$ & 2 & $13 \%$ & 0 \\
\hline Step 4-B: Extra-curricular information & 13 & $87 \%$ & 1 & $7 \%$ & $80 \%$ \\
\hline \multicolumn{6}{|l|}{ Move 5: Conversation with the audience } \\
\hline Step 5-A: Motivation for further study & 15 & $100 \%$ & 15 & $100 \%$ & $0 \%$ \\
\hline Step 5-B: Future ambition and plan & 15 & $100 \%$ & 15 & $100 \%$ & 0 \\
\hline Step 5-C: Understanding of the discipline & 13 & $87 \%$ & 12 & $80 \%$ & $7 \%$ \\
\hline Step 5-D: Appreciation & 14 & $93 \%$ & 6 & $40 \%$ & $53 \%$ \\
\hline \multicolumn{6}{|l|}{ Move 6: Ending } \\
\hline Step 6-A: Restating the wish & 9 & $60 \%$ & 7 & $67 \%$ & $-7 \%$ \\
\hline Step 6-B: Contribution to society & 14 & $93 \%$ & 8 & $73 \%$ & $20 \%$ \\
\hline Step 6-C: Promising to repay & 11 & $73 \%$ & 0 & $0 \%$ & $73 \%$ \\
\hline Step 6-D: Ending & 2 & $13 \%$ & 2 & $13 \%$ & $0 \%$ \\
\hline
\end{tabular}

Note: N- numbers; \% -percentage; CA- Chinese applicant; EA- English-speaking applicant; Difference- Difference on percentage (\% of CA- $\%$ of EA). 


\subsection{Move-step Arrangement Differences for Chinese and English-speaking Applicants}

Table 2 shows the frequency of PSs written by Chinese and English-speaking applicants in each step. The percentage is calculated as 'times of a step's appearance/ total number $(15) * 100 \%$ '. Based on the data in Table 2, the findings are as follows:

\section{Move 1, Introduction}

In 'Introduction' (Move 1), Chinese applicants prefer toportray personality-shaping events (93\%),mention their childhood or youth $(73 \%)$ and introduce influence from family $(60 \%)$. In contrast, none of the three is necessary steps for English-speaking applicants, with a percentage of 27\%, 0\%, and 7\% respectively.

Chinese students show a tendency of illustrating their development of interests in chronological order, for example, "Since my childhood...", "In my primary school..." and "Later on, in high school..." When they trace back to their childhood or youth, around $40 \%$ of Chinese applicants described a small event or harsh time. Similarly, they highlighted the influence brought by their family members, such as "My uncle's work aroused my strong interests in it (this field)". Generally speaking, they invest heavily in convincing readers that they have strong and internal motivation for further study.

Instead, English-speaking students express their intentions directly. They used the major space for personality description and intention expressions, such as "I approach my graduate education with enthusiasm, flexibility, open-mindedness, and desire to learn that I believe will serve me equally well". They also express their strengths or needs directly decorations. Without long narration, their average word counts are less than that of Chinese applicants.

\section{Move 2, Reasons to pursue the proposed study}

In explaining the reasons to pursue the proposed study (Move 2), Chinese applicants emphasize the discussion of relevant life experience and non-academic achievements, with the percentage high to $100 \%$ and $87 \%$ respectively.

It worth noticing that even though all the participants covered the step 'motivation for further study' (Step 2-E), Chinese and English-speaking applicants focused on different aspects: Chinese applicants tent to show intrinsic motivation while the English-speaking applicants are fine with extrinsic motivation. Chinese applicants say they wish to study for knowledge, for problem-solving, for gap-filling, and improvement of their own or the society. In contrast, English-speaking applicants admit that they apply to learn for a higher degree or better job opportunities. Similarly, it seems that Chinese applicants tend to be ashamed of showing egoism. While English-speaking applicants directly say they apply for the study because the course 'serve them well', Chinese applicants used long paragraphs to express their intention of getting a degree out of altruism, namely learn to make contributions to the society. This author does not intend to hint that Chinese applicants are more altruistic or more intrinsicallymotivated. However, it is safe to say that the two groups of applicants value different issues in their application.

\section{Move 3, Evidence of academic qualification}

Conversely and significantly, English-speaking applicants put more effort into giving evidence of academic qualification (Move 3). Compare with Chinese, 40\% more English-speaking students mentioned research experience and 7\% more highlighted professional achievements. Since the postgraduate study focuses on academic exploration, academic ability should be laid special emphasis on; however, only $47 \%$ of Chinese applicants mentioned research experience or professional achievements. The underlying reasons leading to this situation are worth exploring.

\section{Move 4 and Move 5, Other information and conversation with the audience}

In Move 4 and 5, Chinese applicants show obvious differences in two steps: giving extra-curricular information (87\%, while that of English-speaking applicants is 7\%) and showing appreciation for the institution/project/programme (93\%, while that of English-speaking applicants is $40 \%$ ).

Almost all the PSs by Chinese applicants talked about extra-curricular activities in detail, while English-speaking applicants emphasize on in-curricular information (see Table 2).

Chinese students also revealed a high level of humbleness, which reflected from the selection of words in appreciating the institution or project. The frequently used words are "favourite", "it's my honour", "I long admired", etc. Besides, long sentences with strong affection appear high frequency in PSs of Chinese applicants, which is very rare in English-speaking applicants'. For example, Chinese applicants use sentences like "I'm eagerly anxious and hope I'll have the honour to study in your distinguished university", while English-speaking applicants focus more on their own ("I am highly aware of the superb reputation of your school, and my conversations with several of your alumni have served to deepen my interest in attending").

\section{Move 6, Ending}


Chinese and English-speaking applicants show no significant differences in Ending (Move 6) except the step of "Promising to repay" (Step 6-C). Applicants tended to restate their wishes (CA: "I hope you will give me the privilege of continuing my studies at your fine institution"), illustrate their possible contribution to the world (CA: "Thus I can make the world a better place" and EA: "improving the standard of English in my country would help and mould students to be prepared for their future in the world at large"), and end politely (CA:"I hope to hear a favorable response and I would like to thank you in advance for your consideration").

Interestingly, in Step 6-C, up to $73 \%$ of the Chinese promised to make contributions to the university/institution, which is covered by $0 \%$ of English-speaking applications. Chinese applicants presented words and expressions such as "sponsor... my alma mater", "bring surprises to your community" and "contribute to your university" (see examples below). It can be inferred that some Chinese applicants believe admission officers are more possible to select students who can bring actual benefits to the school, so high possibilities of being successful will improve their chances. The underlying psychology is worth further exploration in future studies.

The characteristics of PSs written by Chinese applicants and English-speaking applicants have been listed in Table 3 , as well as the corresponding examples.

Table 3.Characteristics and examples of PSs by CAs and EAs

Characteristic

Childhood/Youth

Chronological order

Small events vs. Concrete experience

Influence from family members Altruism vs. Egoism

Intrinsic motivation vs. Extrinsic motivation

Extracurricular activities vs. Incurricular information

Strong affection vs. neutral affection

Promise to repay the university Example CA: "...my talent in math and physics began to emerge since I was a little kid."

CA: "The first time I saw an English movie, I was totally fascinated by the beautiful musical tone, and I started to speak English to myself, of course, pretended so. That naïve girl lived 20 years ago. 10 years ago..."

CA: "Cherish every drop of water' is one of the fundamental virtues I have learned from my respected teachers, which has set a positive example for my manners. Accordingly, I turn off the faucet conveniently every year. The realization of the invisible power of teacher carries me with conviction."

EA: "I enjoy teaching and interacting with my students. I have been a music teacher for 9 years, and prior to that, a student counsellor at KDU College for 5 1/2 years. My years of teaching have strengthened my belief that teaching is what suits me best."

CA: "I was born into a family with an engineering background."

CA: "At that time, the fields almost harvested nothing. What startled me more was the serious starvation in South Africa covered on TV. Suddenly, I realized that..."

EA: "I approach my graduate business education with enthusiasm, flexibility, openmindedness and desire to learn that I believe will serve me equally well."

CA (For knowledge): "I am lack of sufficient knowledge, so..."

CA (For problem-solving): "The health system in China has two major problems" or "In volunteer activities, I was shocked by the current situation of China's..."

CA (To fill gaps): "However, after almost six years of English teaching, I have also realized several limitations in China's TESOL field”.

CA (To make improvements): "I am lack of sufficient knowledge, so..." or "I feel like I have less to offer and it's time for improvement."

EA (For job opportunities): "I chose this project because there is a greater demand for English lecturers in my country."

EA (For degree): "I want to obtain my Master's degree from a world-class university".

CA: "I also took part in many relevant extracurricular activities to enrich myself in - the field of marketing ...During college life, I have worked in... for 3 months. Meanwhile, I have worked as a team leader.... In the second year of my undergraduate study, I took part in..."

EA: "When I began my undergraduate career, I had the opportunity to be exposed to the full range of courses, all of which tended to reinforce and solidify my intense interest in engineering."

CA: "I'm eagerly anxious and hope I'll have the honor to study in your distinguished university."

EA: "I am highly aware of the superb reputation of your school, and my conversations with several of your alumni have served to deepen my interest in attending."

CA: "I will try my best to contribute toyour university"

CA: "... I believe that I can make a contribution and bring surprises to your community." 
CA: "I also wish to return to campus upon graduating to sponsor the development of my alma mater, and repay the valuable institution that helped me attain my goals."

\subsection{Differences on Word Distribution for Chinese and English-speaking Applicants}

As presented in Table 4, PSs written by Chinese applicants exceed the standards of line count, character count, and word count. Averagely, the lines in PSs by Chinese applicants are 80, almost two times as long as that by Englishspeaking applicants $(n=41)$, while the suggested standard is 47 lines. As to characters of the writing, PSs by Chinese applicants are high to 6307, while the character limit by UCAS standard is 4000 only. The same trend revealed in word limit as well. The word limit is suggested to be 250-650 by Common Application standard (Grove, 2018), but that of Chinese applicants' PSs is 843, with the samples range from 628 words to 1137 words. There are also English-speaking applicants writing a PS exceeding the proposed standards, such as the one with the character of 6158 or the word account 763 . However, only a limited number of PSs by English-speaking applicants generate long documents, and the average lines, characters and word account of PSs by English-speaking applicants meet the standards.

Table 5provides an insight into the word distribution of the two groups on each move. The average word count of PSsby Chinese applicants is 843, while that of English-speaking applicants is 568. Chinese students pay more efforts in Move 1 (Introduction) and Move 5 (Conversation with the audience), with 132 words and 88 words more than the word count used by English-speaking applicants. Significantly, English-speaking applications emphasized giving evidence of academic qualification (Move 3), with an average word count of 150, which is much higher than that of Chinese applicants $(\mathrm{n}=54)$.

Table 4. Average line count, character count and word count of PSs by CA and EA

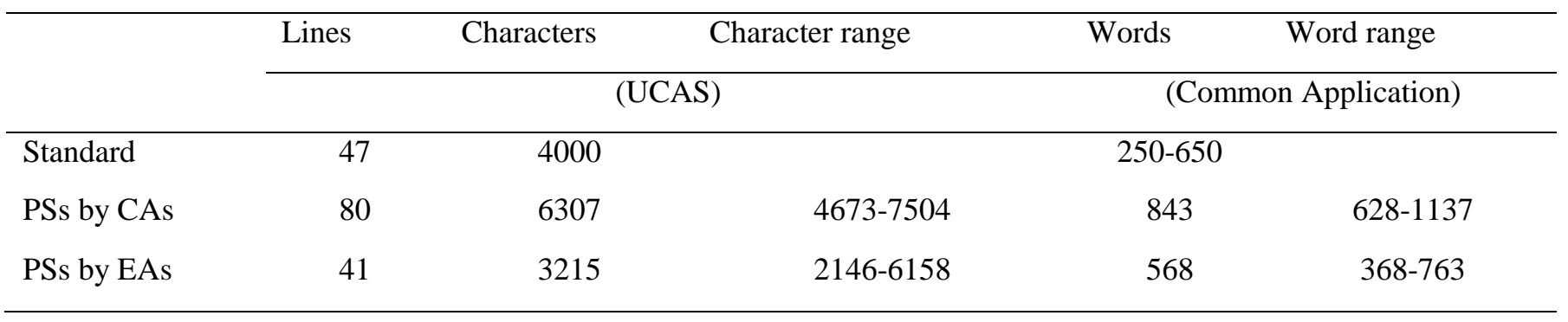

Table 5. The average word count of each move in PSswritten by CA and EA

\begin{tabular}{|c|c|c|c|c|}
\hline Move & & CA & EA & Difference \\
\hline 1: Introduction & & 217 & 85 & 132 \\
\hline 2: Reasons for application & & 164 & 129 & 35 \\
\hline 3. Evidence of academic qualification & & 54 & 150 & -96 \\
\hline 4. Other information & & 75 & 57 & 18 \\
\hline 5. Conversation with the audience & & 146 & 58 & 88 \\
\hline \multirow[t]{2}{*}{ 6.Ending } & & 113 & 53 & 60 \\
\hline & In total & 843 & 568 & 275 \\
\hline
\end{tabular}

\section{Discussion}

\subsection{Differences of PSs Written by Chinese and English-speaking applicants}

In summary, Chinese applicants tend to write long PSs (on average 843 words), which exceed the standards valued by native English speakers. Their word distribution laid emphasis on discussing relevant life experience and nonacademic achievements instead of academic experience showed a tendency of mentioning childhood and family influence, and have a high level of humility, which is reflected in the choice of gap-filling strategy, the use of appreciating words, promising repayment and high level of appreciation to the institution or the project. In contrast, English-speaking applicants tend to present a PS with short length (averagely 568 words), express their intention directly without telling long stories, and free to express their needs and ambition. 
Findings of this study can explain the inconsistency of previous findings by Ding (2007) and Chiu (2016). Ding (2007)conducted a discourse analysis of 30 PSs for medical/dental study and established a move-step framework involving "Explaining reasons, Credentials, Relevant experiences, Stating goal, and Personality"(p. 373). Since the study did not consider Chinese applicants, there are no steps related with Chinese characteristics. Differently, Chiu (2016)analyzed 21 doctoral PSs from education projects, among which there are four written by Chinese applicants. As a result, Chiu (2016) established a framework with "Step 3-A: Gap in Application Background" and "Step 5-D: Praise for Academics/project/institution" (p. 52), which is with high frequency in PSs written by Chinese applicants but low for English-speaking applicants. This author proposes that the PSs written by Chinese and Englishspeaking applicants are with different patterns, and future studies should consider the differences between the two groups before generating move-step frameworks.

Furthermore, the contribution of this study is that it focused on the study of PSs for the Master's application, guaranteed the authenticity of samples, established a detailed and verified framework for reference, and examined the move-step arrangement of PSs written by Chinese and English-speaking applicants in detail. This study also indicated that that the analysis of PSs should extend from the linguistic concept move to step to achieve more accurate results: according to the collected data in this study, Chinese and English-speaking applicants almost cover the same moves but significantly different steps.

\subsection{Word Limit and Word Distribution}

One of the most significant findings of this research is that the word count of PSs written by Chinese applicants exceeds standards. It is hypothesized that the exceeded word count can be caused by three reasons:

Firstly, writing agencies provide misleading instructions to Chinese applicants in PS writing. There is a lack of proper online guidance to offer systematic directions, discipline-specific samples, or personalized advice (Brown, 2004; J. Liu, 2012). As a result, applicants turn to writing agencies for professional assistance. Maybe considered PSs for doctoral application, maybe for the verified needs of different institutions, or the pursuit of higher payment, workers in writing agencies such as Funderburk (2018) propose that a PSshould be between 500-1000 words.

Secondly, Chinese applicantsmisinterpret the standards proposed by the media. Some authoritative media are stating that "it is ok to submit long PSs (if your PS is outstanding)"(BBC, 2016), which weakens the awareness ofword limit control. It is also possible for applicants to misinterpret the standards since the media might regard a 700-word PS as a long one, while that for applicants can be 1400 words or more. Due to the influences brought by professional agencies and media, even though some applicants know the standards, they still tend to write long PSswith 800-1000 words. This inference can explain why OfferMachine (2012)indicates "many universities set the word limit as 300-500 words", and immediately makes a contradictory statement that "PSsshould be around 800 words".

Thirdly, the occluded nature of PSs, which means the materials or feedbacks are not available for open access, leads to mixed standards. Word count is not the only assessment criterion, so even though some applicants exceeded the standards they can also be accepted for other competitive advantages. Therefore, it is possible for Chinese applicants to think a long-long PS with 800-1000 words is acceptable for the admission committee. On word distribution, Chinese applicants assigned more on other five moves instead of the move 'academic qualification'.

The possible reason is that the Chinese students at the undergraduate stage curriculum mainly focuses on knowledge accumulation during the undergraduate study, while English-speaking students receive academic training at the same stage. Since English-speaking applicants tend to be more aware of the importance of academic research and their research interest, they talk more in the move'academic qualification'. However, based on the limited study scope of this research, it is difficult to generalize reasons for these differences, so the exact explanations should be confirmed via interviews in future research.

To be noted, even though this study formed a move-step framework for PS writing, the main aim is to provide applicants with topics to cover. Since the framework is based on a limited number of samples $(n=30)$, it is not proper to be used as writing models. Besides, PS written by Chinese applicants are analyzed with criticism. This paper does not consider their PSs as inferior or disadvantageous ones; instead, this study provides Chinese students with an awareness of their writing characteristics, and enable them to enhance or weaken their characterized writing according to their own will.

\section{Conclusion}

This study aims to analyze the move-step selection and word count differences for PSs written by Chinese and English-speaking applicants. The findings indicate that Chinese applicants tend to write long essays which exceed standards. To be specific, they investigate the major efforts in illustrating bio-history instead of academic 
experience. The move-step analysis tells that PSs written by Chinese and English-speaking applicants are different, and future research should consider it in generalizing move-step frameworks in the future, as well as in cultural differences analysis.

The implications of this study reflect in three ways: firstly, instructors are suggested to consider standards in English-speakingcountries in shaping a PS for application in English-speaking universities or institutions; secondly, teachers are suggested to help students to cut down the word count of PSs to 250-650; thirdly, applicants are suggested to consider writing more in academic experience qualification instead of illustrating life stories in applying for the Master's study.

The limitation of this study is the difficulty of generalization on this specific genre of academic writing. Together with the fact that there always are exceptions in free-style writing, the findings can only represent the participants in this study or a portion of PS writers. Future studies can analyze the efficiency of using different moves or steps and the impact of long PSs written by Chinese applicants from the perspectives of admission officers. The discourse analysis with the discourse analysis method is also recommended for better understanding ofthe underlying socio-cultural and social identity issues.

\section{List of abbreviations}

PS: personal statement; CA: Chinese applicant; EA: English-speaking applicant

\section{Availability of data and materials}

The datasets generated and analysed during the current study are not publicly available due to the ethical principles but are available from the corresponding author on reasonable request.

\section{Reference}

BBC. (2016). Ni Wen Wo Da: Ruhe Xie Gerenchenshu [Q\&A: How to Write a Personal Statement]. Retrieved 07 April 2019, from https://www.bbc.com/ukchina/simp/cool_britannia/uk_qa/2016/08/160803_qa_personal_statement

Bhatia, V. K. (2014). Analysing genre: Language use in professional settings: Routledge. https://doi.org/10.4324/9781315844992

Brown, R. M. (2004). Self-composed: Rhetoric in psychology personal statements. Written Communication, 21(3), 242-260.https://doi.org/10.1177/0741088304264338

Bu, F. (2008). Chuguoliuxue Gerenchenshu de Ticaifenxi [Genre Analysis of Personal Statement in Application of Studying Abroad]. Journal of Harbin University, 29(08), 103-105. https://doi.org/10.3969/j.issn.10092447.2008.02.016

Chiu, Y.-L. T. (2015). Personal statement in PhD applications: Gatekeepers' evaluative perspectives. Journal of English for Academic Purposes, 17, 63-73.https://doi.org/10.1016/j.jeap.2015.02.002

Chiu, Y.-L. T. (2016). 'Singing your tune': Genre structure and writer identity in personal statements for doctoral applications. Journal of English for Academic Purposes, 21, 48-59. https://doi.org/10.1016/j.jeap.2015.11.001

Connor, U., Davis, K. W., \& De Rycker, T. (1995). Correctness and clarity in applying for overseas jobs: A crosscultural analysis of US and Flemish applications. Text-Interdisciplinary Journal for the Study of Discourse, 15(4), 457-476.https://doi.org/10.1515/text.1.1995.15.4.457

Crimson, H. (2004). 50 successful Harvard application essays:what worked for them can help you get into the college of your choice. (Reprinted from St. Martin's Griffin.)

Ding, H. (2007). Genre analysis of personal statements: Analysis of moves in application essays to medical and dental schools. English for Specific Purposes, 26(3), 368-392.https://doi.org/10.1016/j.esp.2006.09.004

Dudley-Evans, T., St John, M. J., \& Saint John, M. J. (1998). Developments in English for specific purposes: A multi-disciplinary approach: Cambridge University Press.

Fan, H., \& Wang, X. (2008). Gerenchenshu de Ticaifenxi [Genre Analysis of Personal Statements] (Master's Dissertation, Journal of Northwestern Polytechnical University).

Funderburk, A. (2018). Working with a Personal Statement Word Count Limit. Retrieved 08 April 2019, from https://www.essayedge.com/blog/word-count-limits/

Grove, A. (2018). The Length Requirements for the Common Application Essay in 2018: Learn About the Maximum Word Count for Your Personal Statement. Retrieved 08 April 2019, from https://www.thoughtco.com/length-requirements-for-2013-application-essay-3970957 
He, X. (2010). Zhongguoren he Meiguoren de Gerencheshu Ticai de Duibifenxi [A Contrastive Genre Analysis of Personal Statements Written by Chinese Applicants and American Applicants] (Master's Dissertation, Chongqing University).

Henry, A., \& Roseberry, R. L. (1997). An investigation of the functions, strategies and linguistic features of the introductions and conclusions of essays. System, 25(4), 479-495.https://doi.org/10.1016/S0346251X(97)00047-X

Lee, A. G., Golnik, K. C., Oetting, T. A., Beaver, H. A., Boldt, H. C., Olson, R., . . . Carter, K. (2008). Reengineering the resident applicant selection process in ophthalmology: a literature review and recommendations for improvement. Survey of ophthalmology, 53(2), 164-176. https://doi.org/10.1016/j.survophthal.2007.12.007

Li, Y., \& Deng, L. (2019). I am what I have written: A case study of identity construction in and through personal statement writing. Journal of English for Academic Purposes, 37, 70-87. https://doi.org/10.1016/j.jeap.2018.11.005

Lim, J. M.-H. (2019). Explicit and implicit justifications of experimental procedures in language education: Pedagogical implications of studying expert writers' communicative resources. Journal of English for Academic Purposes, 37, 34-51.https://doi.org/10.1016/j.jeap.2018.10.006

Liu, J. (2012). Jiyu Ticai de Zhongmei Xuesheng Gerenchenshu Yupian Duibi Fenxi [A Comparative Analysis of Personal Statements Written by Chinese and American Applicants Based on Genre Analysis] (Master's Dissertation, Heilongjiang University).

Liu, T. (2008). Gerenchenshu Ticaifenxi [Genre Analysis of Personal Statements]. Journal of Hubei University of Education, 25(9), 32-34.http://doi.org/10.3969/j.issn.1674-344X.2008.09.010

Max, B. A., Gelfand, B., Brooks, M. R., Beckerly, R., \& Segal, S. (2010). Have personal statements become impersonal? An evaluation of personal statements in anesthesiology residency applications. Journal of clinical anesthesia, 22(5), 346-351.https://doi.org/10.1016/j.jclinane.2009.10.007

Nodoushan, M. A. S., \& Montazeran, H. (2012). The book review genre: A structural move analysis: ERIC Clearinghouse.

OfferMachine. (2012). Pandian Yinguo Liuxueshenqing Gerenchenshu (PS) Xiezuo Tongbing [The Common Problems of Personal Statement Writing for the Application to British Universities]. Retrieved 07 April 2019, from http://www.indexedu.com/201202/5842.html

Ostapenko, L., Schonhardt-Bailey, C., Sublette, J. W., Smink, D. S., \& Osman, N. Y. (2018). Textual analysis of general surgery residency personal statements: topics and gender differences. Journal of surgical education, 75(3), 573-581.https://doi.org/10.1016/j.jsurg.2017.09.021

Sexton, B. (2018). UCAS Personal Statement Word Limit. Retrieved 07 April 2019, from https://www.allaboutlaw.co.uk/stage/law-personal-statement/ucas-personal-statement-word-limit

Swales, J. (1990). Genre analysis: English in academic and research settings: Cambridge University Press.

Swales, J. (1996). Occluded Genres In the Academy: The case of the Submission Letter." Academic Writing: Intercultural and Textual Issues. Eds. Eija Ventola and Anna Mauranen. https://doi.org/10.1075/pbns.41.06swa

Swales, J., Feak, C., Barton, E., \& Brown, R. (2004). Personal statements: a conversation with John Swales and Chris Feak. Issues in Writing, 15(1), 5.

Swales, J. M., \& Feak, C. B. (1994). Academic writing for graduate students. Ann Arbor: University of Michigan Press.

TheShare. (2018). Gerenchenshu You Shenme Yaoqiu? [What are the requirements of the writing of personal statements?]. Retrieved 07 April 2019, from http://www.theshare.cn/article/detailp/2585

Xu, J. (2014). Zhognxifang Yingwen Gerenchenshu de Duibiyanjiu [A Comparative Study of Personal Statements Written by Chinese Students and Native English Speakers]. Journal of Huainan Normal University, 16(5), 56-60.http://doi.org/10.3969/j.issn.1009-9530.2014.05.012 